\title{
Colors, Contrasts and Typography in the Design of ecourses
}

Janko Zufic, Ivan Pogarcic

Department of Educational Sciences

Juraj Dobrila University of Pula

Zagrebacka 30, 52100 Pula, Croatia

\{jzufic,pogarcic\}@unipu.hr

\begin{abstract}
Course's designers are facing great challenges related to readability and acceptable design. They need to account for graphic elements like colors, contents and screen backgrounds, contrasts, typography, number of rows and columns and also for type and place for every single element within the web page. This work discusses also elements of the web pages that would enhance readability for users that suffer from certain visual disorders like dichromacy, i.e. its types like deuteranopia (daltonism), protanopia and tritanopia.
\end{abstract}

Keywords: e-Course, Graphic Elements, Colors, Visual Disorders

Received: 10 October 2018, Revised 3 January 2019, Accepted 18 January 2019

DOI: $10.6025 / \mathrm{jmpt} / 2019 / 10 / 2 / 62-68$

\section{(C) 2019 DLINE. All Rights Reserved}

\section{Introduction}

Due to the obvious advantages of distance learning, such as learning at any time (24/7), learning from any place (with the Internet access) and ultimately cheaper learning, Learning Management System - LMS is becoming increasingly popular, and it is often used for educational purposes, training, training/education of employees of various professions. However, in terms of graphic design not all LMSs are equally effective as teaching tools.

This article will discuss the principles of graphics that make the design of the website's readable and effective for learning. These elements comprise of the color of the teaching content and the color of the background, number of columns and rows, as well as the manner in which the graphically designed elements are embedded within a website. The aim of graphic design is to create an organized and predictable visual structure in which content will be logically divided and presented. The color and contrast in typography (the art and craft of creating text by using different font styles and sizes and different horizontal and vertical spacing between letters [1]) play a key role. When comparing the graphic design of books and websites, it should be emphasized that Web pages differ from books and other documents in one crucial aspect: hypertext links allow users to

\begin{tabular}{llllll}
\hline 62 & Journal of Multimedia Processing and Technologies & Volume & 10 & Number 2 & June \\
\hline
\end{tabular}


experience a single web page separate from its context. For this reason, web pages need to be more independent than pages in a book [2]. Additionally, a significant percentage of the mainly male population (about $8 \%$ of male and less than $0.5 \%$ of the female population [3]), have some sort of color vision deficiency. This article will briefly summarize the issues and proposals in a design that will reduce these obstacles.

\section{Ecourses Design}

In website and eCourse design it is necessary to first select the technology that will be used. Common tools are HTML, PHP, JavaScript, some of the CMS (content management system, for example, the most widely used WordPress, Joomla or Drupal), and for design itself, the most commonly used is CSS (Cascading Style Sheets) as it enables the separation of document content from document presentation, including elements such as the layout, colors and fonts [4].

\subsection{Main Elements of the site and basic Design}

Currently, the classic web design, although it is not entirely the same, contains several main units: a header, a content area and footer.

The header contains the logo (identity), navigation to return to the home page, search area - the search field of web pages, navigation links, and navigation cards.

The content area consists of two to three large columns. Navigation links are located on the left side, main content is in the middle while the right side is optional and it depends on the content of the website and the needs of the website. Footer contains the contact information and the copyright.

\subsection{Visual Design}

Web pages must not be overloaded, as they might confuse the visitors. Designers need to take into account the spacing, grouping, similarity and overall visual logic of the patterns. The main purpose of graphic design is to create a visual hierarchy of contrast in order to determine at first glance what is important and what is not, to define the functional areas of the site and to group site elements that are connected in a manner to make the structure of the content visible. At the same time, there must be consistency on the entire web site and on all web pages.

\subsection{Common mistakes in Web Design}

a) Illegibility of the text due to low contrast, which is reflected in the placement of graphic elements under the text or due to the lack of contrast between the content and the background.

b) Incompatibility of the design between the pages - pages must have the same design.

c) Excessive use of graphics and animation - visitors of the website expect information and not entertainment through Splash, intro or opening animation. They serve only as distraction.

d) Excessive use of different fonts and colors of text. It is necessary to choose 1-2 fonts and up to 2 colors for the text.

e) Non-marking of visited links - everyone knows how visited links look. Failure to meet the expected standards, discourages visitors.

f) Large blocks of text - Need to divide them into paragraphs which will comprise three to four sentences. Between passages it is necessary to leave an empty line.

g) Only one polished browser - when designing a website it is necessary to continuously watch how the website will look in different browsers: Internet Explorer, Mozilla Firefox, Google Chrome, Opera and others because not all browsers display content in the same way [5].

\subsection{Typography and Emphasis}

The key element in the web design is typography. The elements of typography are legibility, alignment and white space, line 
length, leading, type color, typefaces, type size and emphasis.

The ways to emphases individual textual contents of the website are: italic type, bold type, underline type, color type and ALL CAPS.

\section{Role of Colors in Ecourses}

Color is an equally important feature in the web design as it is in the eCourse design. Basic (primary) colors in the additive, luminous model are red, green and blue. By mixing these primary colors, we can get all other colors.

Although the contrast is at its maximum in black and white combinations of colors of content and colors of background, such sites would probably be boring and would not attract many visitors.

Gutierrez stated that it is necessary to think about your target audience when choosing your color scheme. Keep age, nationality, culture and perhaps, gender and mind. Youngsters, for example, appreciate more vivid and brighter colors, while elder people find sober and reserved colors more attractive [6].

\subsection{Contrast and color}

One of the important aspects of the selection of colors is a strong contrast between the background color and what is in the foreground. The contrast makes reading easer. In fact the contrast between the text and the background is exactly what users will see.

In the research on the effectiveness of learning, in relation to the color of the content and color of the background, on 30 different combinations of browser-safe colors, Zufic and Kalpic [7] experimentally determined that the black color of the content on the light yellow background and yellow content on blue-green background are more effective than the referral combination of the printed content in black color on a white background.

In 1987, Murch (see [8]) measured the readability and obtained results indicated that black text on a green background was the best and it was followed by blue text on white background. In 1997, Hill and Scharff (see [8]) confirmed that the best readability was achieved by the combination of black text on green background. Hall and Hannah (see [8]) reported in 2004 the effects of background and font combinations on readability of educational websites black text on white background.

\subsection{Principles of contrast in Web Design}

Web developer Jones [9] lists several principles of contrast in the web design. He mentions contrast in following contexts:

a) Contrast in Color - Colors of the header, content area and footer have to be different. Colors can also be used in establishing the hierarchy of the structure of the text.

b) Contrast in Size - When structure of the text and its emphasis cannot be established by colors, use a different size of the text.

c) Contrast in Alignment - Good alignment plays a big part in creating a quality web design. Things just look better when they line up. This type of contrast should be used sparingly and checked to make sure it shows correctly in different browsers.

\subsection{Recommendations for the selection of colors in eCourse design}

Various authors and designers make similar recommendations for color schemes in eCourses design. Below are some of the most important:

a) Use dark colors for text Black text on a white background or black text on green background or Blue text on white background or alternatively White text on a black background.

b) Neutral colors (grays or pastels) for backgrounds Avoid blue-orange, red-green, blue-yellow color combinations for text and background. Avoid overuse of primary colors. Ensure that the gray background maximizes contrast. Recommended ratio of the luminance contrast between text and background should be at least 3:1.

64 Journal of Multimedia Processing and Technologies Volume 10 Number 2 June 2019 
c) Visual cueing - Use contrasting colors (relative to background), highlighting, arrow pointers, larger fonts, icons to draw attention to key information. Keep consistent color coding (one color per concept) and to a minimum [8].

\subsection{Color vision Deficiency}

The literature mentions that around $8 \%$ of the population (mainly male) has some sort of color vision deficiency [16]. The most common types of color vision deficiencies are:

a) Monochromacy - people lack the ability to distinguish colors and can only see light and dark shades of gray - it is an extremely rare disorder;

b) Dichromacy - a disorder in which a person can distinguish only between two of the three primary colors - it affects up to $2.4 \%$ of the general population, mainly male; and

c) Anomalous trichromacy - a disorder in which people see all the primary colors but have a problem distinguishing shades of certain primary colors - it affects up to $6.3 \%$ of the population, mainly male.

Dichromacy is a color vision deficiency in which a person can distinguish only between two colors, i.e. all the stimuli of colors can be equated with appropriate mixture of only two primary stimuli. The subtypes of dichromacy are:

a) Protanopia - type Dalton - inability to see the color red;

b) Deuteranopia - type Nagel - inability to see the color green, and with

c) Tritanopie - inability to see colors blue and yellow, while seeing red and green. [10]

Figure 1. How a person with protanopia sees the picture

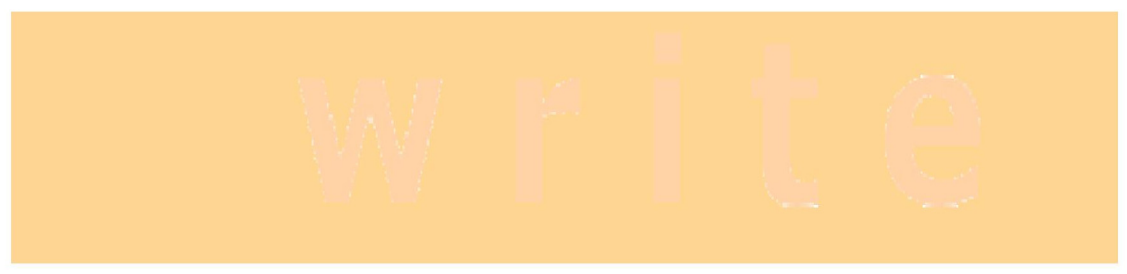

Figure 2. How a person with deuteranopia sees the picture

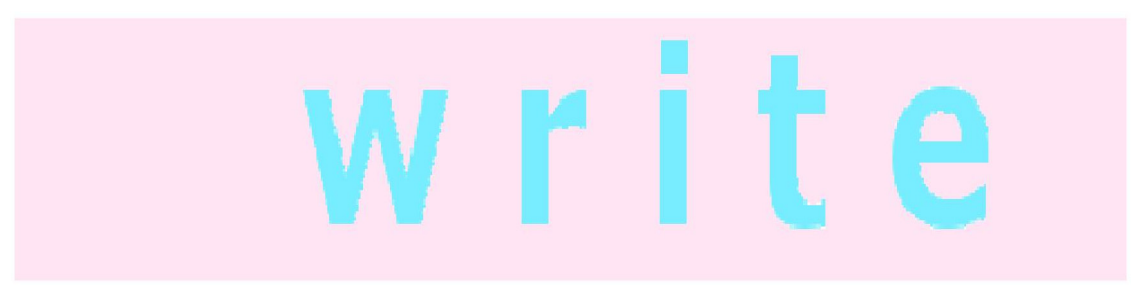

Figure 3. How a person with tritanopia sees the picture 


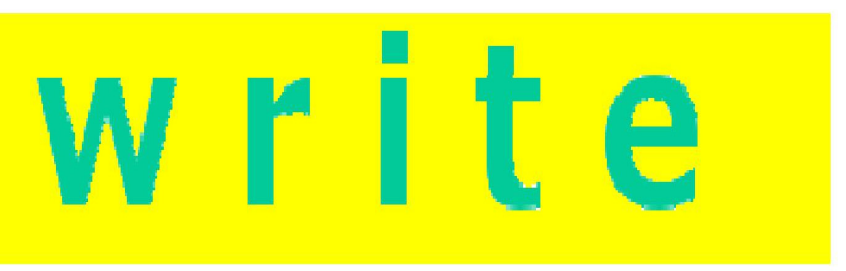

Figure 4. How a person with normal vision sees the picture

In cases where visitors of web pages have a color vision deficiency, increasing contrast of the colors, i.e. adding gray color (in image editing programs such as Adobe PhotoShop or Gimp), for example, in cases of protanopia, putting gray instead of red color, will significantly improve the readibility of the content. Figures 5, 6 and 7 present how persons with color vision deficiencies can see the text after the addition of gray color.

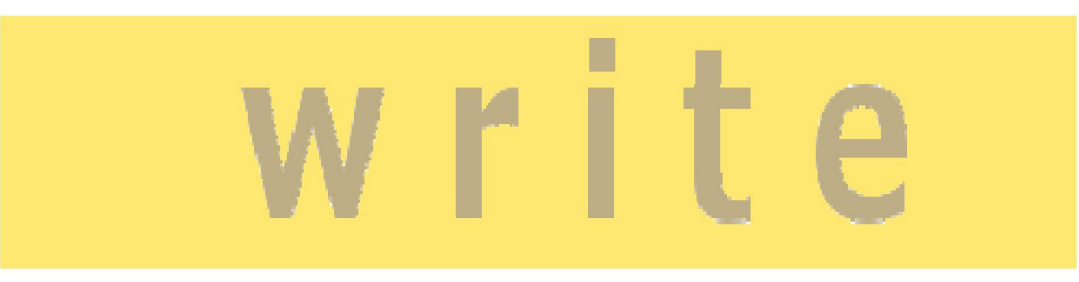

Figure 5. How a person with protanopia sees the picture with increased contrast

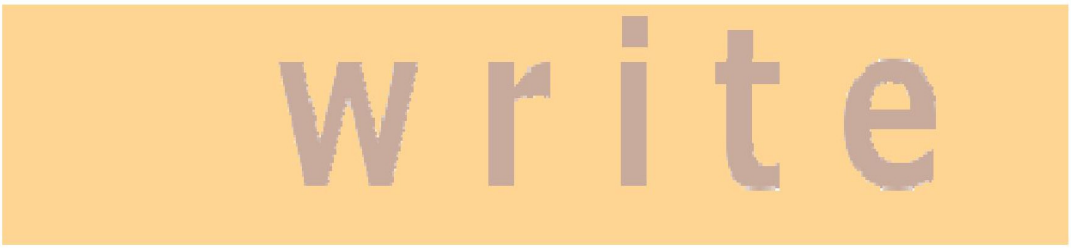

Figure 6. How a person with deuteranopia sees the picture with increased contrast
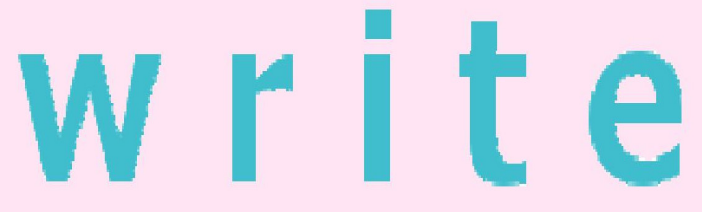

Figure 7. How a person with tritanopia sees the picture with increased contrast

\subsection{How should the eCourse look}

As the eCourse designer does not know in advance who will visit the web pages, the best way to do it is to design all five combinations: one for people with normal vision, one for people with monochromacy and three for people with dichromacy. For visitors suffering from anomalous trichromacy, the same design will be used as for people with normal vision. Therefore, the entire design should be based on three main colors with the mutually good contrasting.

Using CSS in web design makes this task pretty simple. Visitors with color vision deficiency can select the option to change colors. By selecting the combination that best fits their needs, colors of the entire eCourse can be changed.

Therefore, it is best to set the highest contrast difference between content and background. There is also a risk of having a web designer suffering from the color vision deficiency. Internet provides tools for checking contrasts between used colors for

66 Journal of Multimedia Processing and Technologies Volume 10 Number 2 June 2019


contents and backgrounds. An example of such a program is AccessColor and The Color Laboratory. AccessColor checks, on the recommendation of the $\mathrm{W} 3 \mathrm{C}$ [11], two parameters: Color brightness and Color difference.

Color brightness is determined by the formula

$$
((\text { Red value X 299) + (Green value X 587) + (Blue value X 114)) / } 1000
$$

Color difference is determined by the formula

(maximum (Red value 1, Red value 2) - minimum (Red value 1, Red value 2)) + (maximum (Green value 1, Green value 2) - minimum (Green value 1, Green value 2)) + (maximum (Blue value 1, Blue value 2) minimum (Blue value 1, Blue value 2))

The range for color brightness difference is 125 . The range for color difference is 500 .

Note: The values for red, green and blue colors are values used by the RGB color model [11].

The Color Laboratory actually allows you to check out how colors look in conjunction with each other so you can easily create color schemes that work well for anyone - sufferer or not - on any operating system [15].

In some cases it may not be possible to use the mentioned recommendations. In that case, it is best to choose brown background. Brown background goes well with any lighter or darker color. The eCourse should contain images and animations. Questions to be answered before inserting pictures are:

a) Does the image / animation add value to the text?

b) Is the picture / animation relevant? and

c) Does the image / animation instigate interest in eCourse users?

Images SHOULD NOT be converted to black and white and it is NOT necessary to avoid them. In most cases images do not need to be changed, but it is important that the colors are not the only method of providing information. A good example for explanation of the aforementioned are maps or road maps where colors are the primary indicator for different types of roads. In addition to the marking of roads by various colors, it is also useful to enter additional text or otherwise allow users a better understanding of the content [12].

More on how to design a website and an eCourse for people with disabilities can be found at the source [13].

\section{Examples of Good Ecourses}

One of the examples of good courses is internationally recognized website www.coursera.org/

Good examples of websites in Croatian language are the websites of the National Portal for Distance Learning 'Nikola Tesla' (simple design, white background, darker text, purple titles) at tesla.carnet.hr and "Portal znanja" with math instructions titled "Where maths is fun" (a multitude of video clips) available at www.tonimilun.com

\section{Conclusion}

Colors of the content and contrasts in the Web sites we design have a large, primarily aesthetic and sometimes even an essential role. The colors are what is first noticed and they affect how web sites and eCourses are perceived. It is recommended to choose three main colors that will recur throughout the site and that will be mutually contrasting.

For people suffering from color vision deficiencies, it is necessary to adapt design to their needs. CSS is the best 'program' for that. In determining the adequate value of Color brightness and color difference when designing a website it is desirable to use some of the programs such as AccessColor. 
The World Wide Web Consortium (W3C) is an international community of web users whose mission is to establish common standards for the structure and operation of the World Wide Web (http://www.w3.org/) Strategy and further recommendations of the $\mathrm{W} 3 \mathrm{C}$ for the Web design for people with disabilities can be found at the source [14].

\section{References}

[1] Tipografija. hr.wikipedia.org/wiki/Tipografija down load May 5th 2015

[2] Lynch, P. J., Horton, S. Web Style Guide: Basic Design Principles for Creating Web Sites, http://www. webstyleguide.com/ wsg3/index.html 2009. download May 5th 2015

[3] Lalovic, Z. Web pristupa nost, Specijalna biblioteka za slijepa i slabovidna lica Republike Srpske, Banja Luka, http://www.bsrs.rs/ sites/default/files/files/Veb_pristupacnost.pdf 2011. download May 5th 2015. In Serbian

[4] World Wide Web Consortium. What is CSS?, http://www.w3.org/standards/webdesign/htmlcss\#whatcss 2010. download May 5th 2015.

[5] 10 najveih grešaka u web dizajnu http://www. izradainternetstranica.net/dizajn_web_stranica/10_najvecih_gresaka.html In Croatian

[6] Gutierrez, K. (2015). The eLearning Designer's Most Important Decisions, SHIFT's eLearning Blog, http://info.shiftelearning. com/blog/bid/333029/The-eLearning-Designer-s-Most-Important-Decisions 2014. download May 5th 2015

[7] Zufic, J., Kalpic, D. (2011). Boja i efikasnije e-pou avanje, Metodi ki obzori - asopis za odgojno-obrazovnu teorijui praksu.4 (7-8), 57-72 Pula, 2011. (In Croatian)

[8] Richardson, R. T., Drexler, T. L., Delparte, D. M. (2014). Color and Contrast in E-Learning Design: A Review of the Literature and Recommendations for Instructional Designers and Web Developers, MERLOT Journal of Online Learning and Teaching 10 (4) 657-670.

[9] Jones, H. (2015). The Principle of Contrast in Web Design, http://webdesignledger.com/tips/the-principle-ofcontrast-inweb-design 2010. download May 5th 2015.

[10] Rogošic, V. (2003). Defective colour vision, Archives of Industrial Hygiene and Toxicology, 54, 141-144. Zagreb, 2003.

[11] Techniques For Accessibility Evaluation And Repair Tools - W3C Working Draft, (26 April 2000) http://www.w3.org/TR/ 2000/WD-AERT-20000426download May 5th 2015

[12] Juri i, V. (2004). Pregled moguih problema s vidom i mogunosti rada na ra unalu, Faculty of Electrical Engineering and Computing, University of Zagreb. 2004. In Croatian.

[13] WAI: Strategies, guidelines, resources to make the Web accessible to people with disabilities http://www.w3.org/WAI/ intro/people-use-web/Overview.html download May 5th 2015

[14] Web Accessibility Initiative http://www.w3.org/WAI/WCAG20/glance/ download May 5th 2015

[15] Turnbull, C. (2015). Design theory: Designing For, and As, a Color-Blind Person, http://webdesign.tutsplus.com/articles/ designing-for-and-as-a-color-blind-person - webdesign-3408 2011. downloaded May 5th 2015.

[16] Xin Bei, V., Chan, Goh Shi Min, S., Tan Ngiap Chuan. (2014). Subjects With Colour Vision Deficiency In The Community: What Do Primary Care Physicians Need To Know?. Asia Pacific Family Medicine 13, 1-20. 